\title{
EDITORIAL
}

\section{In This Issue: Generalist Care Around the World}

\author{
Jobn J. Frey III, MD, Associate Editor \\ Ann Fam Med 2015;13:406-408. doi: 10.1370/afm.1847.
}

$\mathrm{O}$ ne of the important lessons we have learned over the years is that understanding the context of care is essential for understanding the relevance of studies. ${ }^{1}$ No context could be more important than the health system in the country in which the research takes place. Since this issue of the Annals has articles from 7 different countries, one challenge is how these studies might be generalizable. Despite the differences in health systems, it is remarkable to see how the process of care in generalist practice continues to have as much in common as it has differences.

\section{COMPLEXITY}

From the United States, Loeb and colleagues ${ }^{2}$ use interviews with clinicians to help better define the nature of complex patients, who represent an increasing percentage of patients in primary care practices. They found that a mix of medical, behavioral, and socioeconomic problems were the chief characteristics that determined patient complexity. Their findings challenged the algorithmic approaches to determining complexity used by health systems and insurers. Many of the factors that clinicians felt affected complexity the most, such as homelessness, social isolation, and disability, are not easily found in EHR and billing systems.

In a study by Pati and colleagues ${ }^{3}$ on the prevalence of multimorbidity in a large sample of primary care practices in India, 28\% of patients suffer from multiple physical and mental health problems, which is consistent with prevalence studies around the world. The burdens of primary care will grow in developing countries as generalists there are being challenged with issues of managing complexity similar to those in more developed countries.

In a 4-year study of HIV-positive patients in Ontario, Kendall and colleagues report that most HIV patients are receiving anti-retroviral therapy (ART) from family doctors as HIV treatment moves more into the community. ${ }^{4}$ Their study also shows that family doctors who take care of more HIV-positive patients in the context of their regular practice are more likely to adhere to ART protocols than those who care for fewer, which likely has parallels in managing other complex conditions.

In an attempt to understand the paradox of primary care, Homa and colleagues ${ }^{5}$ developed a computerized simulation of neighborhoods and health care systems with input and collaboration from patients in similar real communities. The simulation-available for others to use and adapt—used examples of primary care and specialty care in fairly straightforward single illness conditions and in situations where a high degree of multimorbidity and complexity existed. The paradox persists: where there is complexity and adequate primary care, patients do better, while the simulation shows that patients with a single health problem do better in specialty care. But the world is moving toward more complex care and the role of the generalist will be more crucial than ever.

\section{THE PERILS OF PRACTICE TRIALS}

Solberg and colleagues engaged in a rigorous implementation of collaborative care for mental health-our Journal Club offering this issue, ${ }^{6}$ — based on data from previous work that showed positive results. ${ }^{7}$ Dissemination and implementation are the greatest challenges facing translational research and highlight the difficulty in improving patient outcomes through practice change. In their dissemination process, practices changed their model of care but depression in the patients in those practices did not improve. One concern, however, is that it may be some time between a change in delivery of care and its effect on measurable clinical benchmarks.

Finch and colleagues ${ }^{8}$ report possible reasons that a practice-based research network (PBRN) intervention might encounter unexpected problems. They highlight challenges in making a national pediatric PBRN operate effectively, focusing on recruitment of practices that are likely to have a profile that would suit the research and having sufficient face-to-face communication to reassure practices that the PBRN, not individual practices, will bear the burden of research. 
In a review of screening tools for cancer prevention by Walker and colleagues, most studies, as well as screening techniques those studies use to improve patient understanding of risks and benefits, showed that, indeed, patients increased their understanding. ${ }^{9}$ Patient behavior regarding getting screened, however, didn't change. Perhaps we need to ask patients more actively about obstacles and their suggestions for overcoming them.

The article by Magill and colleagues look at the financial costs of implementation of patient-centered medical home guidelines in health system-sponsored practices in Utah compared with individual small practices in Colorado. ${ }^{10}$ The cost, as most of us might guess, is quite large-over $\$ 100,000$ per full time equivalent physician per year-with some differences between states. Supporting overhead costs to improve care from a fee-for-service system that rewards throughput rather than quality measures is the wrong way to support practice changes. Large systems may have the capital to invest, but whether they do or not is often variable Small groups have to invest in changes with the hope that the funding for primary care will be supported, eventually, through capitation that includes the cost of the personnel and processes to create patient and community-centered medical practices. That may be a leap of faith that many groups cannot or will not take.

\section{HEART FAILURE}

An article in this issue looks at approaches to treatment of patients with congestive heart failure. Glogowska and colleagues ${ }^{11}$ interviewed heart failure specialty nurses, looking for barriers to effective care. They report that problematic communication with patients and inconsistent communication in care teams are the greatest cause for concern. Their findings support that doctor, nurse, patient, and family have to be involved for effective care. This would be a good situation to use the simulation described by Homa and colleagues and include the variable of high and low communication to see how it might change the curve of care. ${ }^{5}$

\section{IATROGENESIS AND THE ELDERLY}

We all know that aging and its predictable multimorbidity carries with it an increased risk of medicationrelated side effects and falls. New Zealand's national data set for no-fault accident insurance permitted investigators to examine treatment-related accidents. Wallis reports that antibiotics are the largest source of injury claims in the elderly.12 As she writes, "the greatest threat to older patient safety in primary care (is) not error, but the risk posed by treatment itself."

\section{END OF LIFE AND MEANING IN MEDICINE}

Finally, this issue includes a report from the Netherlands by Bolt and colleagues on patient experiences and symptoms when they voluntarily choose to forgo eating and drinking at the end of life (VSED). ${ }^{13}$ The survey of family physicians showed a majority (62\%) had been part of a family and patient's plan to forgo eating and drinking at the end of life. This high percentage is likely because Dutch family doctors do much of their work in communities and home care. The intimate involvement of these family doctors provided the data for the study. Palliative care is a growing field within family medicine around the world and with an aging population that is increasing rapidly, we can expect this issue to be more visible in the communities where we practice.

VSED presents ethical quandaries as well as practice issues in end of life care. In Point/Counterpoint essays in this issue, Quill and Jansen grapple with the question, "Voluntary stopping of eating and drinking, physicianassisted suicide, or neither in the last stage of life?"14,15

In an essay in this issue, a young physician reflects on the quiet California highway where he rediscovered the fundamental humanity at the core of his work. ${ }^{16}$

To read or post commentaries in response to this article, see it online at http://www.annfammed.org/content/13/5/406.

Submitted July 25, 2015; accepted July 26, 2015.

\section{References}

1. Tomoaia-Cotisel A, Scammon DL, Waitzman NJ, et al. Context matters: the experience of 14 research teams in systematically reporting contextual factors important for practice change. Ann Fam Med. 2013;11(Suppl 1):S115-S123.

2. Loeb DF, Binswanger I, Candrian C, Bayliss EA. Primary care physician insights into a typology of the complex patient in primary care. Ann Fam Med. 2015;13(5):451-455.

3. Pati S, Swain S, Hussain M, Kadam S, Salisbury C. Prevalence, correlates, and outcomes of multimorbidity among patients attending primary care in Odisha, India. Ann Fam Med. 2015;13(5):446-450.

4. Kendall CE, Manuel DG, Younger J, Hogg W, Glazier RH, Taljaard M. A population-based study evaluating family physicians' HIV experience and care of people living with HIV in Ontario. Ann Fam Med. 2015;13(5):436-445.

5. Homa L, Rose J, Hovmand PS, et al. A participatory model of the paradox of primary care. Ann Fam Med. 2015;13(5):456-465.

6. Stange, KS. Implementation science is challenging: when RCT evidence doesn't translate into practice [Annals Journal Club]. Ann Fam Med;13(5)iii.

7. Solberg LI, Crain AL, Maciosek MV, et al. A stepped wedge evaluation of an initiative to spread the collaborative care model for depression in primary care. Ann Fam Med. 2015;13(5):412-420.

8. Finch SA, Wasserman R, Nabi-Burza E, Hipple B, Oldendick R, Winickoff JP. Overcoming challenges in the changing environment of practice-based research. Ann Fam Med. 2015;13(5):475-479.

9. Walker JG, Licqurish S, Chiang P, Pirotta M, Emery J. Cancer risk assessment tools in primary care: a systematic review of randomized controlled trials. Ann Fam Med. 2015;13(5):480-489. 
10. Magill MK, Ehrenberger D, Scammon DL, et al. The cost of sustaining a patient-centered medical home: experience from 2 states. Ann Fam Med. 2015;13(5):429-435.

11. Glogowska M, Simmonds R, McLachlan S, et al. Managing patients with heart failure: a qualitative study ofmultidisciplinary teams with specialist heart failure nurses. Ann Fam Med. 2015;13(5):466-471.

12. Wallis KA. Learning from no-fault treatment injury claims to improve the safety of older patients. Ann Fam Med. 2015;13(5):472-474.

13. Bolt EE, Hagens M, Willems D, Onwuteaka-Philipsen B. Primary care patients hastening death by voluntarily stopping eating and drinking. Ann Fam Med. 2015;13(5):421-428.
14. Quill TE. Voluntary stopping of eating and drinking (VSED), physician-assisted death (PAD), or neither in the last stage of life? Both should be available as a last resort. Ann Fam Med. 2015;13(5):408-409.

15. Jansen LA. Voluntary stopping of eating and drinking (VSED), physician-assisted suicide (PAS), or neither in the last stage of life? PAS: no; VSED: it depends. Ann Fam Med. 2015;13(5):410-411.

16. Kohler JE. I'm a doctor. Can I help? Ann Fam Med. 2015;13(5): 490-491.

\title{
POINTICOUNTERPOINT
}

\section{Voluntary Stopping of Eating and Drinking (VSED), Physician-Assisted Death (PAD), or Neither in the Last Stage of Life? Both Should be Available as a Last Resort}

\author{
Timothy E. Quill, MD \\ University of Rochester Medical Center, Rochester, New York
}

Ann Fam Med 2015;13:408-409. doi: 10.1370/afm.1850.

A A. was a 60 -year old man with refractory metastatic cancer who requested a palliative care consultation to explore potential future access to physician-assisted death (PAD). (I recommend using the term "physician-assisted death" because from a meaning point of view this practice has nothing to do with "suicide." In fact, for patients like A.A., this option has more to do with self preservation than self destruction.) I initially responded that I could not provide this option because of legal restrictions in New York, but that I would help him find a solution when and if the time came. We explored other legally available "last resort" possibilities ${ }^{1,2}$ including potentially voluntarily stopping eating and drinking (VSED). He

Conflicts of interest: author reports none.

\section{CORRESPONDING AUTHOR}

Timothy E. Quill, MD

University of Rochester Medical Center

School of Medicine and Dentistry

Professor of Medicine, Psychiatry, and Medical

Palliative Care Division, Department of Medicine

601 Elmwood Ave, Box 687

Rochester, NY 14642

Timothy_Quill@URMC.Rochester.edu initially thought that this latter option was nothing a humane society would put its dying patients through, and we agreed to do our best to address whatever the future held for him.

With expert palliative treatment he remained acceptably comfortable and functional over the next year despite widespread skeletal metastases until the day he spontaneously fractured his femoral head. He once again asked for medication to end his life, but instead we braced his leg, increased his analgesia, and sent him home with added hospice support. He returned within 24 hours with a spontaneous hip fracture. Over the next several days, he fractured more bones and experienced serious pain whenever he moved, and he feared more fractures just from turning over in bed. He was prepared for death, and adamantly wanted PAS - the "sooner the better." He was receiving state-of-the-science palliative care, and despite this he was severely suffering both physically and psychologically. We discussed VSED alongside aggressive symptom management as his only option for a hastened death. He again spoke about how absurd and immature this seemed to him in comparison to PAD, but he ultimately accepted this was his "least worst" option. ${ }^{3}$ We maintained pain relief with a concentrated opioid infusion and kept his mouth as moist as possible. 